\title{
An Investigation on Thermal Recycling of Recycled Plastic Resin* (Combustion Characteristics of Polyethylene Terephthalate Resin Powder in a High Temperature Oxidizing Atmosphere)
}

\author{
Ryuji YAMAKITA**, Katsuya MIURA**, Yojiro ISHINO*** and Norio OHIWA***
}

\begin{abstract}
Thermal recycling of recycled plastic resin is focused in this investigation. Fine grinding of plastic resin and preparation of high temperature oxidizing atmosphere are indispensable for effective and successful burn-up of plastic resin. Polyethylene terephthalate resin powder is employed and high temperature oxidizing atmosphere is generated downstream an annular burner. Through a circular nozzle set coaxially in the closed bottom end of the annular burner, PET-powder and propane-air mixture are issued vertically upward into the high temperature oxidizing atmosphere. Temperature and $\mathrm{O}_{2}$ concentration fields downstream the annular burner are first examined by varying the circular jet equivalence ratio with the air flow rate kept constant and without PET-powder supply. PET-powder having a mass-median diameter of either $89.7 \mu \mathrm{m}$ or $145 \mu \mathrm{m}$ is then issued into the high temperature region along with propane-air mixture by varying the PET-powder mass flow rate. Appearances of the PETpowder flame are observed using a high-speed CCD video camera and unburnt PET particles are traced during their passages in the high temperature region. Variation of $\mathrm{O}_{2}$ concentration fields due to PET-powder combustion is also measured in the PET flame. According to the results, overall limit conditions for effective burn-up of PET-powder are finally discussed.
\end{abstract}

Key Words: Combustion, Alternative Energy, Burner, Thermal Recycling, PET Powder, High Temperature Oxidizing Atmosphere

\section{Introduction}

In this investigation the possibility of thermal recycling of recycled plastic resin is examined, since it is considered to be one of the most effective and useful methods to reuse a large quantity of recycled plastic resin consisting of mainly pure hydrocarbon. In order to burn successfully, however, plastic resin should be first crushed into fine particles or powder and introduced into high temperature oxidizing atmosphere. Before designing a burner using plastic resin powder as an alternative or auxiliary fuel, extensively accumulated knowledge concerning pulverized coal combustion $^{(1)-(8)}$ is extremely useful for getting some key points. Comparison of combustion characteristics of pulverized coal to those of plastic resin powder gives the fol-

* Received 21st July, 2004 (No. 04-4167)

** Post Graduate Student, Graduate School of Engineering, Nagoya Institute of Technology, Gokiso-cho, Showa-ku, Nagoya, Aichi 466-8555, Japan

*** Graduate School of Engineering, Nagoya Institute of Technology, Gokiso-cho, Showa-ku, Nagoya, Aichi 4668555, Japan. E-mail: oiwa.norio@nitech.ac.jp lowing two important points; one is that plastic resin has a low melting point and is easy to melt, the other is that plastic resin is free from volatile materials. The former indicates that, in order to prevent plastic resin powder from coagulating on the supply line, it should be supplied under cold circumstances just before entering into the combustion zone. The latter suggests that something substitute is indispensable, which plays the part of volatile materials and prepares high temperature oxidizing circumstances for heating, vaporizing and burning plastic resin powder.

According to these considerations, by employing fine polyethylene terephthalate resin powder (abbreviated to PET-powder in the following) as an auxiliary fuel and propane as a substitute fuel, combustion experiments of PET-powder using a commercial burner for the ceramic kiln furnace have been carried out both in the open and in-furnace operations ${ }^{(9)}$. It was found that, when PETpowder having a mass-median diameter (abbreviated to MMD) of $145 \mu \mathrm{m}$ is supplied to the burner, a large part of PET-powder is exhausted without burn-out in the open atmospheric operation, whereas it is perfectly consumed 
in the in-furnace operation. This fact points out that sufficiently long residence time of PET- powder in the high temperature oxidizing circumstances is of special importance.

Physical behavior of a micro PET particle under stationary and abrupt heating has also been analyzed ${ }^{(10)} \mathrm{ex}-$ perimentally and numerically to estimate the quantitative limit relationship between the residence time and the heating temperature, by assuming the heating process to be spherically symmetric and one-dimensional heating of a floating micro PET particle in the high temperature atmosphere. The theoretical results showed that a micro PET particle having a diameter of $150 \mu \mathrm{m}$ needs about $44 \mathrm{~ms}$ for its complete evaporation at a heating temperature of $1000^{\circ} \mathrm{C}$. This indicates that a rather long passageway is necessary for satisfying the limit condition for effective heating and burn-up of PET-powder; for example, a passageway of about $176 \mathrm{~mm}$ under a constant moving velocity of $4.0 \mathrm{~m} / \mathrm{s}$ and a heating temperature of $1000^{\circ} \mathrm{C}$.

According to those results obtained in the preceding papers ${ }^{(9),(10)}$, an attempt to produce a long and high temperature oxidizing zone is first made and the idea of the annular burner ${ }^{(11),(12)}$ is employed in this investigation. This is because that the annular burner enables easily stable formation of an intense annular flame and exhibits very excellent flame stabilization characteristics. Temperature and $\mathrm{O}_{2}$ concentration fields downstream the annular burner are first measured by varying the equivalence ratio of the circular mixture jet under the condition without PET-powder supply. After examining and determining the optimum circular jet equivalence ratio, PET-powder is issued into the high temperature oxidizing circumstances by varying the mass flow rate with the equivalence ratio and the velocity of the circular jet kept constant at each prescribed value. Variations of flame appearances with the PET-powder mass flow rate are observed using a highspeed CCD video camera. Based on detailed observations, unburnt PET particles are traced during their passages in the high temperature oxidizing regions and their physical and chemical characteristics are examined and, finally, overall characteristics of ignition and combustion of PETpowder are considered.

\section{Nomenclature}

$d:$ diameter of PET particle $[\mu \mathrm{m}]$

$d_{\mathrm{m}}$ : mass median diameter of PET-powder; abbreviated to MMD $[\mu \mathrm{m}]$

$d_{\mathrm{P}}$ : limit diameter of PET particle for burn-up [ $\left.\mu \mathrm{m}\right]$

$L_{\mathrm{c}}$ : major radius of high temperature ellipsoid [mm]

$m_{\mathrm{P}}$ : PET-powder mass flow rate $[\mathrm{g} / \mathrm{min}]$

$Q_{\text {na }}$ : air flow rate of the circular jet [L/min]

$r$ : radial distance from the central axis [mm]

$R_{\mathrm{c}}:$ minor radius of high temperature ellipsoid [mm]

$T:$ temperature $\left[{ }^{\circ} \mathrm{C}\right]$ $v_{\mathrm{n}}:$ circular jet velocity $[\mathrm{m} / \mathrm{s}]$

$v_{\mathrm{s}}:$ slit jet velocity $[\mathrm{m} / \mathrm{s}]$

$z$ : axial distance from the circular nozzle exit [mm] Greek symbols

$\phi_{0}$ : overall equivalence ratio [-]

$\phi_{\mathrm{n}}:$ circular jet equivalence ratio [-]

$\phi_{\mathrm{s}}:$ slit jet equivalence ratio [-]

$\tau:$ life time of a PET particle for evaporation [ms]

\section{Experimental Apparatus and Method}

Schematic diagram of the experimental system is shown in Fig. 1. The system is composed of an annular burner, a propane-air mixture supply line for the annular flame, a supply line for the nozzle flame consisting of a propane-air mixture supply line and a PET-powder supply line, and a series of instruments. The construction and dimensions of the annular burner are given in Fig. 2. The annular burner consists of a vertical and cylindrical tube, four slit nozzles and a circular vertical nozzle. The cylindrical tube has an inner diameter of $50 \mathrm{~mm}$ and a height of $90 \mathrm{~mm}$ and is closed at the section one third upper from the bottom end and open at the upper end. At the central one-third part of the annular burner, four slit nozzles of $2 \mathrm{~mm}$ width and $30 \mathrm{~mm}$ height are set at $90^{\circ}$ intervals, from which propane-air stoichiometric mixture jets are issued tangentially. Due to the limit capacity of the blower

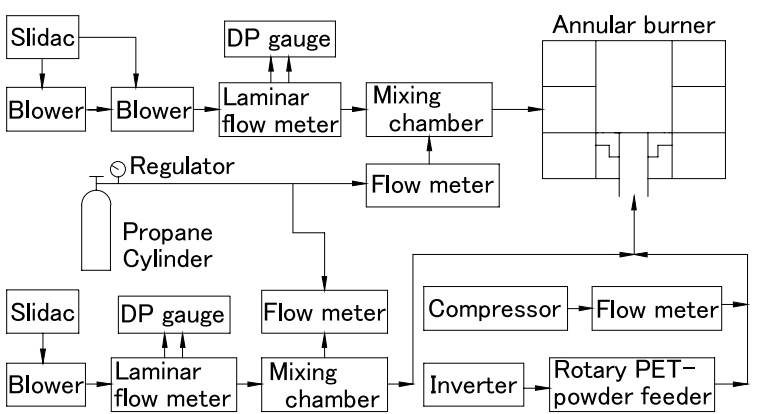

Fig. 1 Schematic diagram of the experimental system

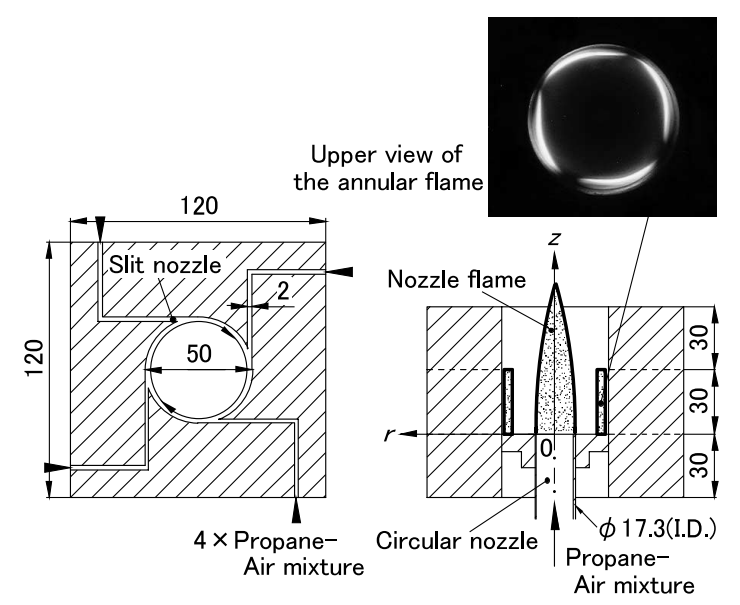

Fig. 2 Construction and dimensions of the annular burner 
Table 1 Setting conditions of the annular burner

\begin{tabular}{c|c}
\hline \multicolumn{2}{c}{ Slit jet properties } \\
\hline Equivalence ratio $\phi_{\mathrm{s}}$ & Velocity $v_{\mathrm{s}} \mathrm{m} / \mathrm{s}$ \\
\hline \multicolumn{2}{c}{ Circular jet properties } \\
\hline \multicolumn{2}{c}{. } \\
\hline \multicolumn{2}{c}{ Equivalence ratio $\phi_{\mathrm{n}} /$} \\
Velocity $v_{\mathrm{n}} \mathrm{m} / \mathrm{s}$ & PET-powder mass \\
\hline $0 / 3.59,0.4 / 3.66,0.8 / 3.72$, & $4.0,8.0,12$ \\
$1.0 / 3.75,1.2 / 3.78,1.6 / 3.84$ & \\
\hline
\end{tabular}

used, the maximum slit jet velocity is limited and fixed to a constant value of $v_{\mathrm{s}}=6.0 \mathrm{~m} / \mathrm{s}$. Four planar mixture jets form four planar premixed flames in a thin annular region adjacent to the burner wall and combine to form an intense annular flame. An example of direct photographs of the annular flame is given in the inset of Fig. 2. The circular nozzle having an inner diameter of $17.3 \mathrm{~mm}$ is also arranged coaxially with the annular burner at the center of the closed end. PET-powder and propane-air mixture are issued vertically upward from the circular nozzle. The PET-powder mass flow rate and the circular jet equivalence ratio are varied as two parameters.

Measurements of temperature and $\mathrm{O}_{2}$ concentration are first carried out with the circular jet equivalence ratio varied and without PET-powder supply. The circular jet equivalence ratio is adjusted by increasing the propane flow rate with the air flow rate kept constant at a maximum value of $Q_{\mathrm{na}}=50.7 \mathrm{~L} / \mathrm{min}$. The operation conditions of the annular burner are summarized in Table 1 . It is found that the mean circular jet velocity increases slightly with increasing the equivalence ratio; $v_{\mathrm{n}}=3.59 \mathrm{~m} / \mathrm{s}$ at $\phi_{\mathrm{n}}=0$ to $v_{\mathrm{n}}=3.84 \mathrm{~m} / \mathrm{s}$ at $\phi_{\mathrm{n}}=1.6$, deviating only $\pm 3.5 \%$ from its mean value. Time-averaged temperature is measured using a fine R-type thermocouple of $0.1 \mathrm{~mm}$ diameter and $\mathrm{O}_{2}$ concentration is detected with an $\mathrm{O}_{2}$-analyzer $(350 \mathrm{M} / \mathrm{XL}$; testo Co., Ltd.), respectively.

Two kinds of PET-powder having a small massmedian diameter (MMD) of $d_{\mathrm{m}}=89.7 \mu \mathrm{m}$ and a large MMD of $d_{\mathrm{m}}=145 \mu \mathrm{m}$ are used as an auxiliary fuel to examine the effect of MMD on burning characteristics and the possibility for achieving effective burn-up. Histograms of two kinds of PET-powder are presented in Fig. 3 and show that the particle diameter distributes over relatively wide ranges of $d=28-320 \mu \mathrm{m}$ and $d=34$ $420 \mu \mathrm{m}$ for PET-powder having an MMD of $d_{\mathrm{m}}=89.7 \mu \mathrm{m}$ and $145 \mu \mathrm{m}$, respectively. For reference, heating properties and conditions of PET-powder are summarized in Table 2 .

PET-powder and propane-air mixture are injected vertically upward from the circular nozzle at nearly constant velocity of $v_{\mathrm{n}}=3.72 \mathrm{~m} / \mathrm{s}$. The PET-powder mass flow rate is varied from $m_{\mathrm{p}}=4.0 \mathrm{~g} / \mathrm{min}$ to $12 \mathrm{~g} / \mathrm{min}$ at $4.0 \mathrm{~g} / \mathrm{min}$ intervals. In order to observe flame appearances and trace
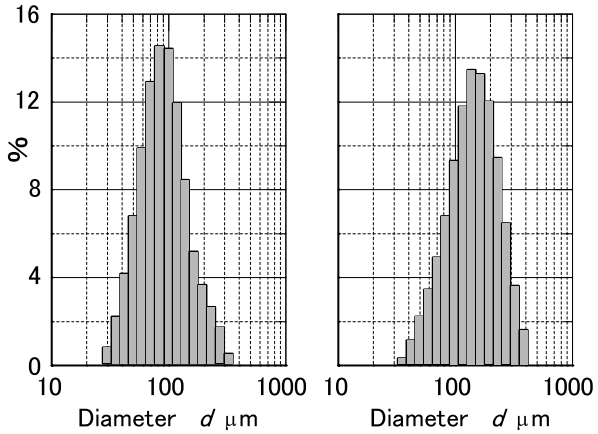

(a) $d_{\mathrm{m}}=89.7 \mu \mathrm{m}$

(b) $d_{\mathrm{m}}=145 \mu \mathrm{m}$

Fig. 3 Histograms of two kinds PET-powder

Table 2 Heating properties and conditions of PET-powder

\begin{tabular}{c||c|c|c}
\hline $\begin{array}{c}\text { PET mass flow rate } \\
m_{\mathrm{p}} \mathrm{g} / \mathrm{min}\end{array}$ & 4.0 & 8.0 & 12.0 \\
\hline $\begin{array}{c}\text { Lower heating value } \\
\mathrm{MJ} / \mathrm{kg}\end{array}$ & \multicolumn{3}{|c}{21.8} \\
\hline Heat input $\mathrm{kW}$ & 1.45 & 2.91 & 4.36 \\
\hline
\end{tabular}

PET particles during their passages in the high temperature oxidizing atmosphere, high-speed photographs are taken for three sets of burning conditions using a highspeed CCD video camera (Photron; FASTCAM-PC1, the maximum framing speed: $1000 \mathrm{fps}$, the minimum exposure time: $16.7 \mu \mathrm{s})$.

\section{Experimental Results}

\subsection{Combustion characteristics without PET- powder supply}

3.1.1 Variation of flame appearances Direct photographs of the annular flame without PET-powder supply are shown in Fig. 4, where the circular jet equivalence ratio is varied as a parameter. The upper and lower pictures give the upper and side views of the flame, respectively. Each upper view clearly shows that four discrete planar blue premixed flames are established downstream of four slit nozzles and form an intense and steady annular flame in the vicinity of the cylindrical wall. Each side view shows that, on the other hand, a blue jet flame is stabilized by the annular flame at the exit of the circular nozzle, which can be seen in the central part of each upper view as indicated by a white arrow, and forms a typical turbulent premixed jet flame downstream the annular burner.

The increase in the circular jet equivalence ratio from $\phi_{\mathrm{n}}=0$ to 1.0 makes an outline of the jet flame at the nozzle exit clear and elongates the overall flame length. Further increase in $\phi_{\mathrm{n}}$ into the fuel-rich region makes overall appearances obscure and elongates the post-flame region, being particular to fuel-rich turbulent jet flames. It is expected here that these changes of flame appearances may yield preferable results for establishing a long and thick 


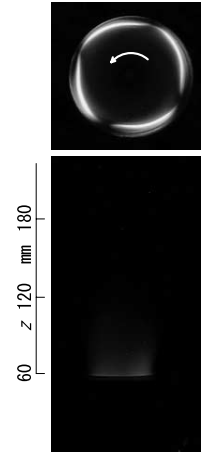

(a) $\phi_{\mathrm{n}}=0$

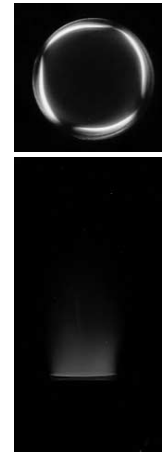

(b) $\phi_{\mathrm{n}}=0.4$

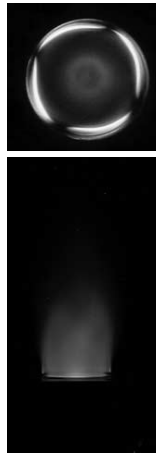

(c) $\phi_{\mathrm{n}}=0.8$

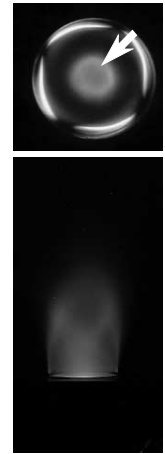

(d) $\phi_{\mathrm{n}}=1.0$

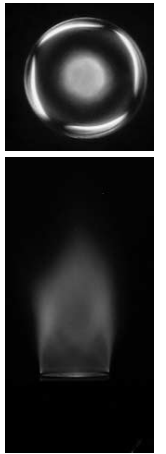

(e) $\phi_{\mathrm{n}}=1.2$

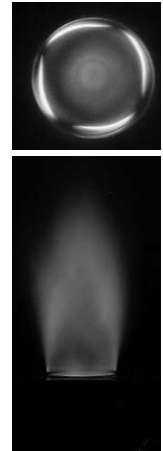

(f) $\phi_{\mathrm{n}}=1.6$

Fig. 4 Variation of flame appearances with the circular jet equivalence ratio

plume-like high temperature zone downstream the annular burner. In the following paragraph temperature and $\mathrm{O}_{2}$ concentration characteristics in the plume-like zone are examined using isothermals and $\mathrm{O}_{2}$ concentration contours.

\subsubsection{Isothermals and $\mathrm{O}_{2}$ concentration contours}

Isothermals and $\mathrm{O}_{2}$ concentration contours measured without PET-powder supply are given in Fig. 5 (a)-(f) for six circular jet conditions given in Table 1 . The left- and right-half of each figure show $\mathrm{O}_{2}$ concentration contours at $5 \%$ intervals and isothermals at $200^{\circ} \mathrm{C}$ intervals, respectively. The circular jet equivalence ratio is varied, whereas the slit jet conditions are kept constant at $v_{\mathrm{s}}=6.0 \mathrm{~m} / \mathrm{s}$ and $\phi_{\mathrm{s}}=1.0$. The average velocity of the circular jet increases only slightly, as already mentioned, with the increase in the circular jet equivalence ratio, being in the range of $v_{\mathrm{n}}$ $=3.59-3.84 \mathrm{~m} / \mathrm{s}$.

Figure 5 shows that, independent of the circular jet equivalence ratio, both profiles downstream the annular burner exhibit Gaussian character; temperature takes a maximum value on the axis and decreases gradually in the radial direction, while $\mathrm{O}_{2}$ concentration takes a minimum value on the axis and increases gradually to the atmospheric value in the radial direction. The size of high temperature zone, which constitutes an elongated semielliptic zone and looks like a plume, first spreads axially and radially with increasing the circular jet equivalence ratio in the fuel-lean region $\left(\phi_{\mathrm{n}}=0.4-1.0\right)$, while the contour of $\mathrm{O}_{2}$ concentration of $5 \%$, for example, becomes longer in the axial direction. This result indicates that, in contrast to temperature characteristics, $\mathrm{O}_{2}$ concentration in the high temperature plume remains low and offers undesirable conditions for successful consumption of PETpowder.

Further increase in the circular jet equivalence ratio into the fuel-rich region, however, reduces the maximum temperature in the central semi-elliptic region and elongates the region containing low $\mathrm{O}_{2}$ concentration. These results suggest the existence of a kind of trading-off relation between the size of high temperature plume and the
$\mathrm{O}_{2}$ concentration within it. From the view point of effective and complete burn-up of PET-powder, simultaneous attainment of high temperature and high $\mathrm{O}_{2}$ concentration is considered to be most necessary and desirable. The trading-off relation, however, obliges to select the following compromise conditions concerning the circular jet properties. Figure 5 indicates that the outline of isothermal of $1050{ }^{\circ} \mathrm{C}$ coincides approximately with that of $\mathrm{O}_{2}$ concentration of $10 \%$ and forms a semi-elliptic region downstream the annular burner. The major and minor radii of the semi-elliptic region increase with increasing the circular jet equivalence ratio from $L_{\mathrm{c}}=100 \mathrm{~mm}$ and $R_{\mathrm{c}}=25 \mathrm{~mm}$ for $\phi_{\mathrm{n}}=0$ to $L_{\mathrm{c}}=230 \mathrm{~mm}$ and $R_{\mathrm{c}}=33 \mathrm{~mm}$ for $\phi_{\mathrm{n}}=1.6$, respectively.

In the preceding investigation ${ }^{(10)}$, the time required for complete evaporation of a micro PET particle under stationary and abrupt heating, defined as the life time $\tau$, was numerically analyzed by varying the particle diameter and the heating temperature. According to the results, the required time for PET particles having a diameter of $d=$ 100,150 and $200 \mu \mathrm{m}$ at a heating temperature of $T=$ $1000^{\circ} \mathrm{C}$ is estimated to be about $\tau=19.5,44.1$ and $78.3 \mathrm{~ms}$, respectively. Since the mean velocity of the circular mixture jet is set at nearly constant value of $v_{\mathrm{n}}=$ $3.72 \mathrm{~m} / \mathrm{s}$ as shown in Table 1 , the necessary passage length for PET particles through the high temperature region of $1000^{\circ} \mathrm{C}$ is simply evaluated as $3.72[\mathrm{~m} / \mathrm{s}] \times(19.5,44.1$, $78.3) \times 10^{-3}[\mathrm{~s}]=(72.5,164,292)[\mathrm{mm}]$, respectively. These values are found to agree well with the range of the major radius of high temperature plume of $L_{\mathrm{c}}=100$ $230 \mathrm{~mm}$.

It is assumed here from the simplified and overall point of view that the advantages of high temperature circumstances higher than $1050^{\circ} \mathrm{C}$ in the reaction kinetics effectively compensate the disadvantages of leaner $\mathrm{O}_{2}$ concentration less than $10 \%$. By taking into account of the fact that PET-powder with an assigned MMD contains a lot of particles larger than the assigned MMD, slight overestimation concerning the limit condition for effective consumption of PET-powder is inevitable in this investiga- 


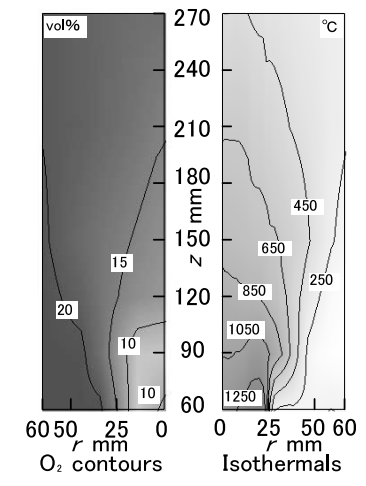

(a) $\phi_{\mathrm{n}}=0, v_{\mathrm{n}}=3.59 \mathrm{~m} / \mathrm{s}$

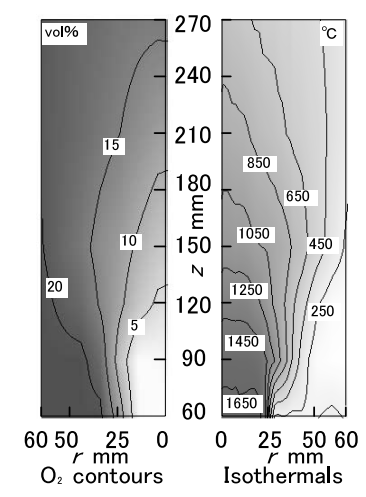

(c) $\phi_{\mathrm{n}}=0.8, v_{\mathrm{n}}=3.72 \mathrm{~m} / \mathrm{s}$

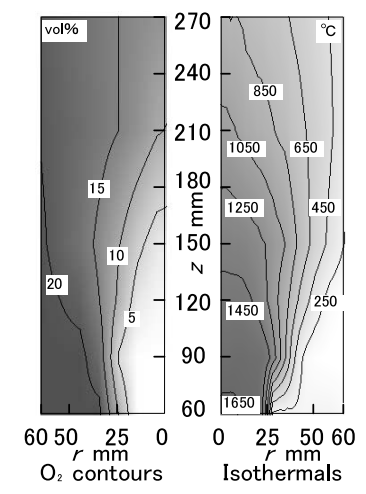

(e) $\phi_{\mathrm{n}}=1.2, v_{\mathrm{n}}=3.78 \mathrm{~m} / \mathrm{s}$

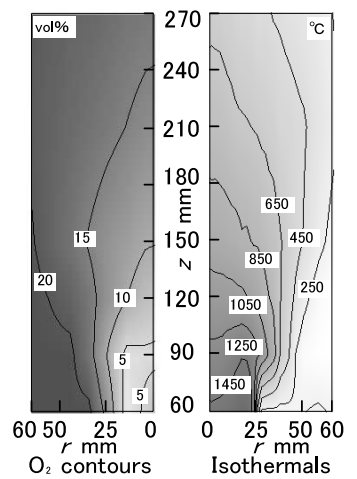

(b) $\phi_{\mathrm{n}}=0.4, v_{\mathrm{n}}=3.66 \mathrm{~m} / \mathrm{s}$

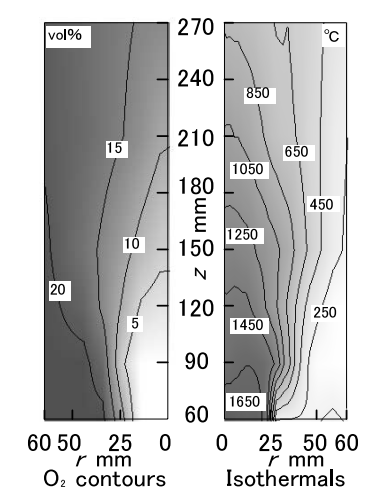

(d) $\phi_{\mathrm{n}}=1.0, v_{\mathrm{n}}=3.75 \mathrm{~m} / \mathrm{s}$

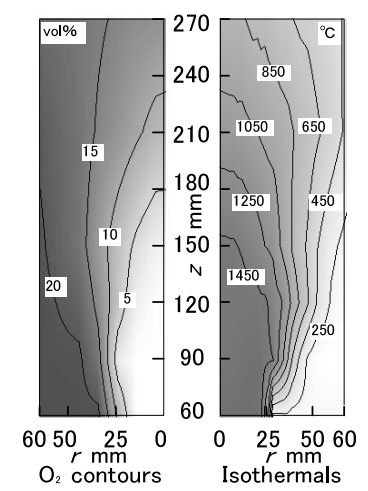

(f) $\phi_{\mathrm{n}}=1.6, v_{\mathrm{n}}=3.84 \mathrm{~m} / \mathrm{s}$

Fig. 5 Isothermals and $\mathrm{O}_{2}$ concentration contours downstream the annular burner without PET-powder supply; $\phi_{\mathrm{s}}=1.0$ and $v_{\mathrm{s}}=6.0 \mathrm{~m} / \mathrm{s}$

tion. The following compromise criterion is then adopted; the residence time through the high temperature oxidizing atmosphere having temperature higher than $1000^{\circ} \mathrm{C}$ and $\mathrm{O}_{2}$ concentration up to $10 \%$ should exceed the life time of PET particles required for complete evaporation.

According to considerations about the interrelation between the residence time in the high temperature oxidizing zone and the particle diameter, the optimum set of limit conditions for PET-powder having a large MMD of $d_{\mathrm{m}}=145 \mu \mathrm{m}$ satisfies, as a matter of course, those for PET-powder having a small MMD of $d_{\mathrm{m}}=89.7 \mu \mathrm{m}$. In order to allow a slight margin in the residence time during the passage through the high temperature region, the opti-

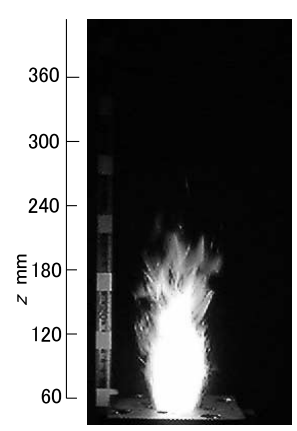

(a) $4.0 \mathrm{~g} / \mathrm{min}$

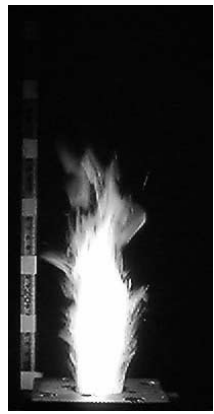

(b) $8.0 \mathrm{~g} / \mathrm{min}$

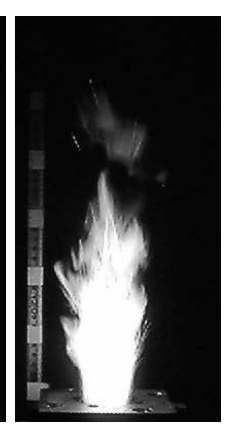

(c) $12 \mathrm{~g} / \mathrm{min}$
Fig. 6 Appearances of flames supplied with PET-powder of an MMD of $d_{\mathrm{m}}=89.7 \mu \mathrm{m}$; an exposure time of $1 / 100 \mathrm{~s}$ for $\phi_{\mathrm{n}}=0.8$ and $v_{\mathrm{n}}=3.72 \mathrm{~m} / \mathrm{s}$

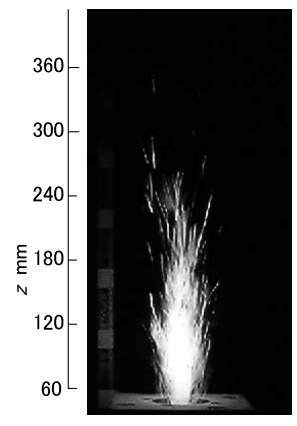

(a) $4.0 \mathrm{~g} / \mathrm{min}$

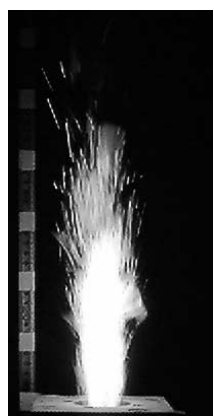

(b) $8.0 \mathrm{~g} / \mathrm{min}$

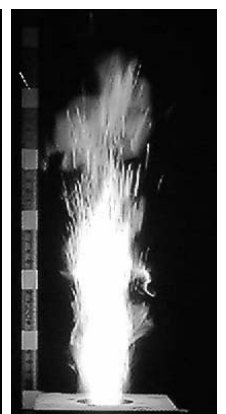

(c) $12 \mathrm{~g} / \mathrm{min}$
Fig. 7 Appearances of flames supplied with PET-powder of an MMD of $d_{\mathrm{m}}=145 \mu \mathrm{m}$; an exposure time of $1 / 100 \mathrm{~s}$ for $\phi_{\mathrm{n}}=0.8$ and $v_{\mathrm{n}}=3.72 \mathrm{~m} / \mathrm{s}$

Table 3 Variation of the overall equivalence ratio with increasing the PET mass flow rate

\begin{tabular}{c|c|c|c}
\hline PET mass flow rate $m_{\mathrm{p}} \mathrm{g} / \mathrm{min}$ & 4.0 & 8.0 & 12 \\
\hline \hline Slit jet equivalence ratio $\phi_{\mathrm{s}}$ & \multicolumn{3}{|c}{1.0} \\
\hline Circular jet Equivalence ratio $\phi_{\mathrm{n}}$ & \multicolumn{3}{|c}{0.8} \\
\hline Overall equivalence ratio $\phi_{0}$ & 1.10 & 1.28 & 1.46 \\
\hline
\end{tabular}

mum circular jet conditions are shifted and determined to be $\phi_{\mathrm{n}}=0.8$ and $v_{\mathrm{n}}=3.72 \mathrm{~m} / \mathrm{s}$.

\subsection{Combustion characteristics with PET-powder} supply

3.2.1 Time-averaged flame appearances Appearances of the flame supplied with PET-powder of an MMD of $d_{\mathrm{m}}=89.7 \mu \mathrm{m}$ and stabilized by the annular burner having the circular jet conditions of $\phi_{\mathrm{n}}=0.8$ and $v_{\mathrm{n}}=3.72 \mathrm{~m} / \mathrm{s}$ are photographed at an exposure time of 1/100 sec and shown in Fig. 6. Those supplied with PETpowder of $d_{\mathrm{m}}=145 \mu \mathrm{m}$ are shown in Fig. 7. In both figures the PET-powder mass flow rate is varied from $m_{\mathrm{p}}=$ $4.0 \mathrm{~g} / \mathrm{min}$ to $12 \mathrm{~g} / \mathrm{min}$ at $4.0 \mathrm{~g} / \mathrm{min}$ intervals. The overall equivalence ratio varies with the PET-powder mass flow rate, as given in Table 3.

Figures 6 and 7 demonstrate that the PET-powder 
flame is composed of yellow gaseous and dense images and multiple incandescent particle-track images, and becomes longer and smoky in the downstream flame region with increasing the mass flow rate and the particle mean diameter. The yellow and dense images correspond to gaseous diffusion flame of PET-vapor originated from those particles which have smaller diameters and evaporate easily and completely during their passages through the high temperature oxidizing atmosphere prepared by the annular burner. As shown in Table 3, the overall equivalence ratio takes a value greater than unity; $\phi_{0}>1$, indicating that PET-powder evaporates and burns in the fuel rich condition. This fact causes incomplete combustion of PET-vapor and leads to the appearance of smoky and sooty images.

The incandescent images, on the other hand, correspond to multiple loci of those particles which have larger diameters and leave the flame region without burn-out. The increase in the MMD from $d_{\mathrm{m}}=89.7$ to $145 \mu \mathrm{m}$ clearly augments the incandescent particle-track images, diminishes the gaseous yellow images, and makes somewhat transparent at the burner exit, resulting in the increase of unburnt PET-powder.

\subsubsection{Influences of PET-powder combustion on $\mathrm{O}_{2}$} concentration fields Although temperature and $\mathrm{O}_{2}$ concentration fields may change significantly due to the PET-powder combustion, multiple and frequent impacts of PET particles and coagulation of PET-vapor on the fine thermocouple and gas sampling probe make measurements of temperature and $\mathrm{O}_{2}$ concentration in the upstream region of the PET flame extremely difficult. In order to prevent PET particles from impacting the thermocouple, $\mathrm{O}_{2}$ concentration profiles across the flame supplied with PET-powder having $d_{\mathrm{m}}=89.7 \mu \mathrm{m}$ are only measured and compared with those obtained without PETpowder supply.

$\mathrm{O}_{2}$ concentration contours are presented in Fig. 8 in the $z-r$ plane, where Fig. 8 (a) gives those for the flame without PET-powder supply and Fig. 8 (b) gives those for the flame supplying with PET-powder at a mass flow rate of $m_{\mathrm{p}}=8.0 \mathrm{~g} / \mathrm{min}$. The circular jet equivalence ratio $\phi_{\mathrm{n}}$ is varied as a parameter. $\mathrm{O}_{2}$ concentration contours depicted in Fig. 8 (c) are constructed by subtracting those in Fig. 8 (a) from those in Fig. 8 (b) and, therefore, express consumed $\mathrm{O}_{2}$ concentration fields due to the PET-powder combustion. $\mathrm{O}_{2}$ contours are drawn at $5.0 \%$ intervals in Fig. 8 (a) and (b), and at 2.0\% intervals in Fig. 8 (c).

According to Fig. 8 (a) and (b), the PET-powder combustion reduces appreciably $\mathrm{O}_{2}$ concentration level in the central high temperature plume and elongates the semielliptic region with low $\mathrm{O}_{2}$ concentration by about 120 $160 \%$. Pronounced reduction is observed in the flame with $\phi_{\mathrm{n}}=0.4$, as shown in Fig. 8 (b). Figure 8 (c) demonstrates directly and clearly these features, together with the infor- mation about the primary region where intense PET-vapor combustion occurs. Almost no oxygen is consumed in the region just downstream the annular burner exit, indicating that the heating process of PET-powder including solid heating, melting, liquid heating and evaporation mainly proceeds there.

The primary burning zone of PET-vapor exists downstream the heating zone and is clearly distinguished by the existence of a detached island of $\mathrm{O}_{2}$ contours in Fig. 8 (c). The smaller the circular jet equivalence ratio becomes, the higher the height of the $\mathrm{O}_{2}$ contour island becomes. The larger the former becomes, on the other hand, the shorter the length of the detached island. The height of the detached island shows concretely that $\mathrm{O}_{2}$ consumption up to $6 \%$ is caused by the PET-vapor combustion in the range of circular jet equivalence ratio of $\phi_{\mathrm{n}}=0.8-1.6$, whereas $\mathrm{O}_{2}$ consumption up to $8 \%$ appears in the PET flame with $\phi_{\mathrm{n}}=0$ and 0.4. Also found is that the location of the detached island of $\mathrm{O}_{2}$ contours moves radially outward with increasing $\phi_{\mathrm{n}}$, showing the PET flame wears more and more diffusible character. These experimental facts clearly suggest that the leaner the circular jet equivalence ratio becomes, the more effective burn-up of PET-powder can be realized.

However, by taking into account of the fact that, as can be seen in Fig. 5, the major radius of high temperature semi-ellipsoid higher than $1050^{\circ} \mathrm{C}$ in the flame having $\phi_{\mathrm{n}}=0-0.8$ is short and the residence time in the semiellipsoid becomes also short compared with those having larger equivalence ratios, it is concluded that, although the condition of high $\mathrm{O}_{2}$ concentration is indeed found to be indispensable for effective burn-up of PET-powder, the high temperature circumstances are also important and effective for quick and through evaporation.

3.2.3 High-speed direct photographs High speed direct photographs of PET-powder flames having an MMD of $d_{\mathrm{m}}=145 \mu \mathrm{m}$ are taken at a framing speed of $1000 \mathrm{fps}$ under the fixed circular jet conditions of $\phi_{\mathrm{n}}=0.8$ and $v_{\mathrm{n}}=3.72 \mathrm{~m} / \mathrm{s}$. A slightly lean mixture is employed for ensuring simultaneous attainment of the high temperature and high $\mathrm{O}_{2}$ concentration conditions. Some examples are shown in Fig. 9 consecutively at $2 \mathrm{~ms}$ intervals for the PET-powder mass flow rate of $m_{\mathrm{p}}=8.0 \mathrm{~g} / \mathrm{min}$. Since overall appearances and features of the PET flame are quite similar to those observed in Figs. 6 and 7, main attention is focused on the temporal behavior of the sooty PET-vapor flame and the locus of an incandescent large PET particle.

As shown by a series of thick arrows in the pictures, a cluster of sooty flame originates just downstream the annular burner and diminishes gradually with its downstream movement. Also shown by a series of circles in the pictures, a cluster of smoky flame which is preceded and/or followed by an atmospheric gulf is consumed relatively 

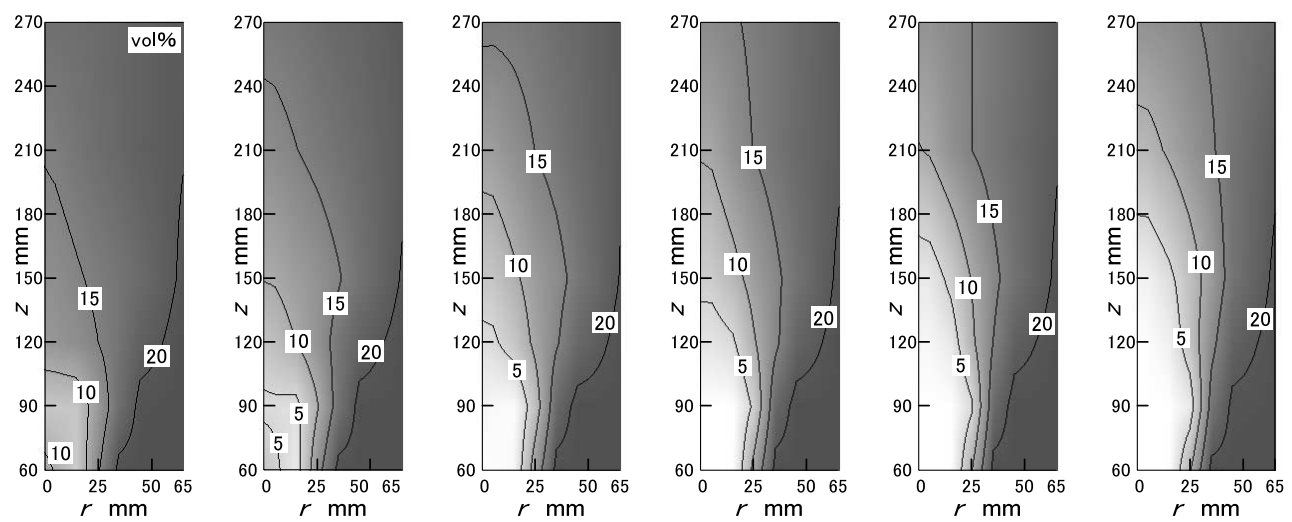

$$
\phi_{\mathrm{n}}=0
$$

$\phi_{\mathrm{n}}=0.4$

$\phi_{\mathrm{n}}=0.8$

$\phi_{\mathrm{n}}=1.0$

$\phi_{\mathrm{n}}=1.2$

$\phi_{\mathrm{n}}=1.6$

(a) $\mathrm{O}_{2}$ contours for the flame without PET-powder supply
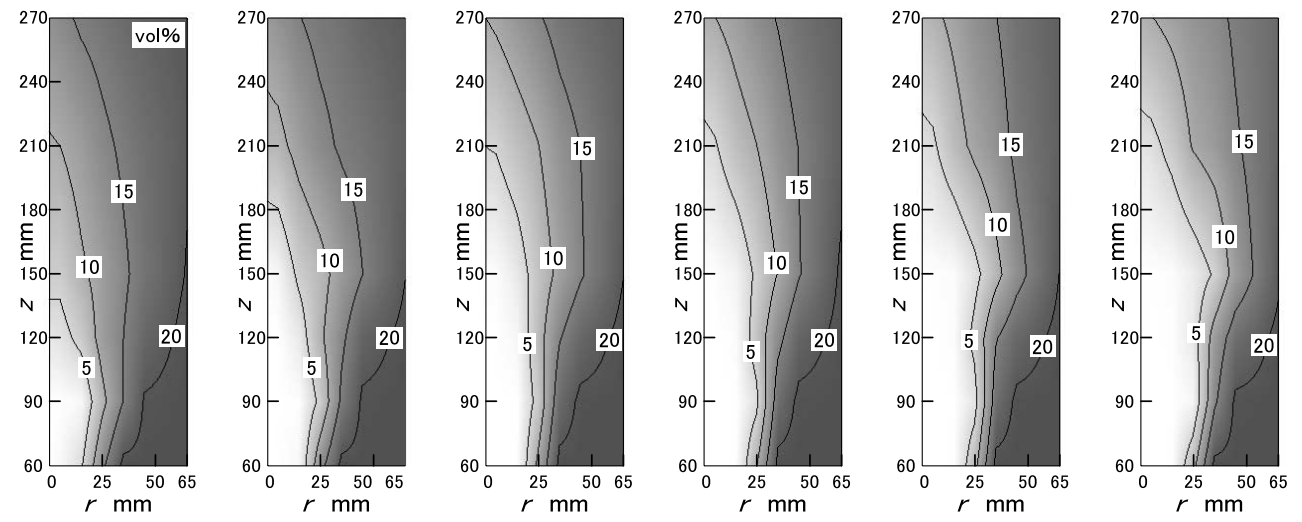

$$
\phi_{\mathrm{n}}=0
$$

$$
\phi_{\mathrm{n}}=0.4
$$

$$
\phi_{\mathrm{n}}=0.8
$$

$$
\phi_{\mathrm{n}}=1.0
$$

$\phi_{\mathrm{n}}=1.2$

$\phi_{\mathrm{n}}=1.6$

(b) $\mathrm{O}_{2}$ contours for the flame with PET-powder supply; $d_{\mathrm{m}}=89.7 \mu \mathrm{m}$ and $m_{\mathrm{p}}=8.0 \mathrm{~g} / \mathrm{min}$
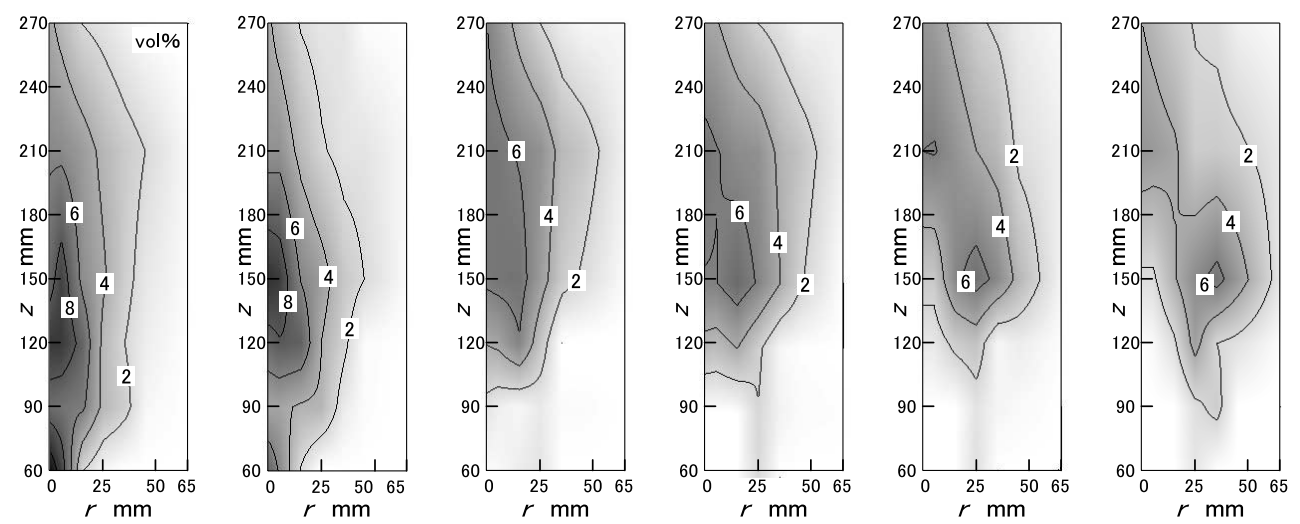

$$
\phi_{\mathrm{n}}=0 \quad \phi_{\mathrm{n}}=0.4
$$

$\phi_{\mathrm{n}}=0.8$

$\phi_{\mathrm{n}}=1.0$

$\phi_{\mathrm{n}}=1.2$

$\phi_{\mathrm{n}}=1.6$

(c) Consumed $\mathrm{O}_{2}$ concentration fields

Fig. 8 Comparison of $\mathrm{O}_{2}$ concentration contours between flames without and with PETpowder supply; $d_{\mathrm{m}}=89.7 \mu \mathrm{m}$ and $m_{\mathrm{p}}=8.0 \mathrm{~g} / \mathrm{min}$

quickly with its downstream movement. These results indicate that PET-vapor emitted from smaller particles than the assigned MMD in the upstream region of the high temperature plume burns as gaseous turbulent diffusion flame and is almost completely consumed in the flame region.
Concerning the multiple loci of incandescent PET particles, two types of loci are distinguished; those burnout and disappear during their passages through the high temperature flame zone, pointed out by the thin arrows in many pictures, and those leave there without burn-out, 


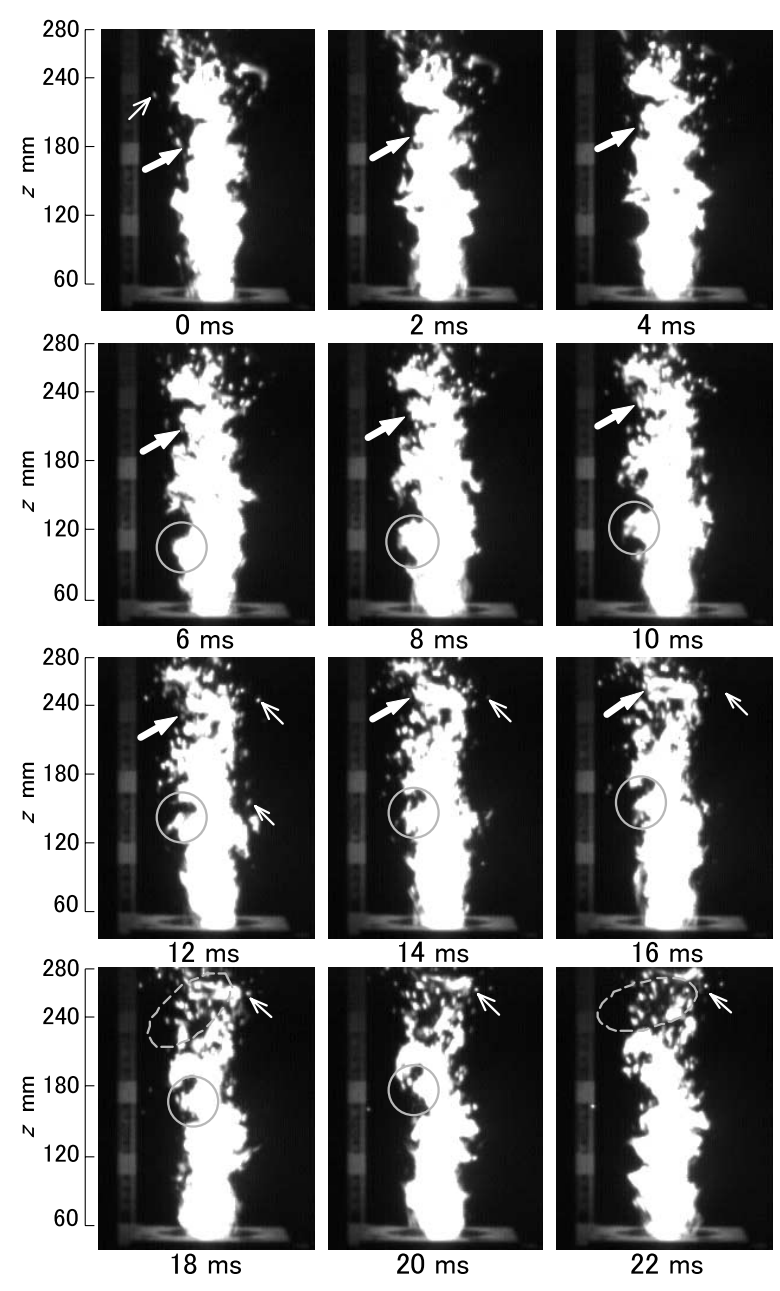

Fig. 9 A series of high-speed direct photographs of a PETpowder flame taken at $1000 \mathrm{fps} ; \phi_{\mathrm{n}}=0.8, v_{\mathrm{n}}=3.72 \mathrm{~m} / \mathrm{s}$, $d_{\mathrm{m}}=145 \mu \mathrm{m}$ and $m_{\mathrm{p}}=8.0 \mathrm{~g} / \mathrm{min}$

shown by the broken ellipsoids in the bottom two pictures. As shown in Fig. 3 (b), PET-powder prescribed by an MMD of $d_{\mathrm{m}}=145 \mu \mathrm{m}$ contains a large quantity of particles having diameter greater than the assigned one. It is considered, therefore, that the former loci come from those particles having diameter near the assigned MMD, whereas the latter loci are due to those particles having diameter greater than the assigned MMD.

\section{Brief Discussion}

The limit criterion for effective burn-up of PETpowder is finally discussed in connection with the size of the high temperature oxidizing region.

According to the result that, as can be seen in Fig. 5, the contour of isothermal of $1050{ }^{\circ} \mathrm{C}$ agrees approximately with that of $\mathrm{O}_{2}$ concentration of $10 \%$, the region surrounded by the contour is now simply regarded as the high temperature oxidizing atmosphere. The limit requirement for complete consumption of PET-powder is defined by the condition whether the residence time of a PETparticle within the high temperature oxidizing region ex-
Table 4 Variations of the residence time and limit diameter with the circular jet equivalence ratio

\begin{tabular}{c|c|c|c|c|c|c}
\hline $\begin{array}{c}\text { Circular jet equivalence } \\
\text { ratio } \phi_{\mathrm{n}}\end{array}$ & 0 & 0.4 & 0.8 & 1.0 & 1.2 & 1.6 \\
\hline Length of contour $L_{\mathrm{c}} \mathrm{mm}$ & 100 & 136 & 180 & 216 & 224 & 230 \\
\hline Residence time $\tau \mathrm{ms}$ & 27.9 & 37.2 & 48.4 & 57.6 & 59.3 & 59.9 \\
\hline Limit diameter $d_{\mathrm{P}} \mu \mathrm{m}$ & 119 & 138 & 157 & 171 & 174 & 175 \\
\hline Heating temperature $T{ }^{\circ} \mathrm{C}$ & \multicolumn{6}{|c}{1000} \\
\hline
\end{tabular}

ceeds the life time for complete evaporation. The residence time is then simply evaluated by dividing the major radius of the high temperature oxidizing ellipsoid $L_{\mathrm{c}}$ by the mean convection velocity $v_{\mathrm{n}}$, and summarized in Table 4. Also listed in Table 4 is the limit particle diameter $d_{\mathrm{P}}$, at which the residence time is equal to the life time at the heating temperature of $1000^{\circ} \mathrm{C}$, based on the numerical simulation concerning the life time of a micro PETparticle for complete evaporation under the abrupt heating without combustion ${ }^{(10)}$.

Table 4 indicates that the circular jet equivalence ratio exerts relatively strong influence on the limit diameter; varying in the range of $d_{\mathrm{p}}=119-175 \mu \mathrm{m}$, and that, by injecting propane-air mixture with an equivalence ratio of $\phi_{\mathrm{n}}=0.8$ from the circular nozzle at a constant velocity of $3.72 \mathrm{~m} / \mathrm{s}$, PET particles having diameter smaller than $160 \mu \mathrm{m}$ can be effectively consumed during their passages through the high temperature oxidizing zone. PET particles having diameter greater than $160 \mu \mathrm{m}$, however, need longer residence time. These quantitative explanations correspond very well to those qualitative considerations about Figs. 6 and 7, and certify the extreme availability of the simplified numerical estimation ${ }^{(10)}$. It is concluded therefore that, when the annular burner is so operated as to ensure both formation of the high temperature and high $\mathrm{O}_{2}$ concentration circumstances and the long residence time within the latter, the proposed idea is extremely useful for the thermal recycling of recycled plastic resin.

\section{Concluding Remarks}

In order to examine the possibility of effective thermal recycling of recycled PET resin, combustion characteristics of the annular burner without and with PETpowder supply are observed and estimated by carrying out the temperature and $\mathrm{O}_{2}$ concentration measurements and high-speed direct observations. Two kinds of PET-powder having a small MMD of $d_{\mathrm{m}}=89.7 \mu \mathrm{m}$ and a large MMD of $d_{\mathrm{m}}=145 \mu \mathrm{m}$ are used. Brief consideration about the quantitative limit conditions for effective burn-up of PETpowder using the annular burner is also made. The results are summarized as follows:

1. The flame formed without PET-powder supply is composed of an intense annular flame and a turbulent pre- 
mixed jet flame stabilized by the former. The increase in the circular jet equivalence ratio $\phi_{\mathrm{n}}$ under the fuel-lean condition makes the size of high temperature region higher than $1050^{\circ} \mathrm{C}$ longer and thicker and rises the maximum temperature up to $1650^{\circ} \mathrm{C}$, leaving $\mathrm{O}_{2}$ concentration low, for example, less than $10 \%$. Under the fuel-rich condition, the increase in $\phi_{\mathrm{n}}$ decreases the maximum temperature, while the size of high temperature zone still becomes longer. It is found that the isothermal of $1050^{\circ} \mathrm{C}$ agrees approximately with the $\mathrm{O}_{2}$ contour of $10 \%$.

2. The PET-powder flame consists of gaseous diffusion flame of PET-vapor, which originates from those particles having smaller diameter and evaporating easily during their passages through high temperature zone, and multiple incandescent particle-track images, which correspond to multiple loci of those particles having larger diameter and leave the flame zone without burn-out. It is found that the smaller the circular jet equivalence ratio becomes, the more prominent the $\mathrm{O}_{2}$ consumption, and that not only the condition of high $\mathrm{O}_{2}$ concentration but also the high temperature condition are important for effective burn-up of PET-powder.

3. The overall limit conditions of the annular burner for effective and complete burn-up of PET-powder having an assigned MMD can be relatively easily evaluated by taking into account of the results from the simplified numerical analysis concerning the abrupt heating of a micro PET particle.

In order to schedule a further investigation and to confirm the possibility of the thermal recycling of recycled plastic resin, improvement of the annular burner is found to be of special importance. The use of other kinds of plastic-resin having different physical and chemical properties as other auxiliary fuels is also indispensable. After scheduling a set of new experimental conditions, detailed observation and measurement will be carried out in the near future.

\section{Acknowledgements}

The authors express their great thanks to Mr. Keisuke Teramoto for his faithful contribution during this investigation.

\section{References}

( 1 ) Kobayashi, H., Howard, J.B. and Sarofim, A.F., Coal
Devolatilization at High Temperatures, Proc. Combust. Inst., Vol.16 (1977), pp.411-425.

( 2 ) Timothy, L.D., Sarofim, A.F. and Beer, J.M., Characteristics of Single Particle Coal Combustion, Proc. Combust. Inst., Vol.19 (1982), pp.1123-1130.

( 3 ) Smoot, L.D., Hedman, P.O. and Smith, P.J., Pulverized Coal Combustion Research at Brigham Young University, Edited by Chigier, N.A., Progress in Energy and Combustion Science, Vol.10, (1984), pp.359-441, Pergamon Press, Oxford.

( 4 ) Okazaki, K., Shishido, H., Nishikawa, T. and Ohtake, K., Characteristics of Pulverized Coal Combustion and NOx Formation in an One- Dimensional Furnace, Trans. Jpn. Soc. Mech. Eng. (in Japanese), Vol.51, No.465, B (1985), pp.1549-1556.

( 5 ) Wall, T.F., Combustion of Coal as Pulverized Flue through Swirl Burners, Edited by Lawn, C.J., Principles of Combustion Engineering for Boilers, Chap. 3, (1987), pp.197-335, Academic Press, London.

( 6 ) Sorensen, L.H., Biede, O. and Peck, R.E., An Experimental Study of High-Temperature Oxidative Pulverized Coal Devolatilization, Proc. Combust. Inst., Vol.25 (1994), pp.475-483.

( 7 ) Taniguchi, M., Kobayashi, H. and Azuhara, S., Laser Ignition and Flame Propagation of Pulverized Coal Dust Clouds, Proc. Combust. Inst., Vol.26 (1996), pp.3189-3195.

( 8 ) Williams, A., Pourkashanian, M. and Jones, J.M., Combustion Mechanism of Pulverized Coal, Combustion and Gasification of Coal, Chap. 4, (1999), pp.86122, Taylor \& Francis, New York.

( 9 ) Ishino, Y., Yamakita, R., Kuroda, S., Kato, M., Yasuda, M. and Ohiwa, N., Combustion Characteristics of a Twin Fuel Ceramic Burner Using Recycled PET-Resin Powder as an Auxiliary Fuel, Proc. 6th ASME-JSME Thermal Eng. Joint Conf., (2003), CD-ROM, Paper No. TED-AJ03-181.

(10) Yamakita, R., Ishino, Y. and Ohiwa, N., High-Speed Direct Microscopic Observations of Ignition and Burning Processes of a Micro Plastic-Resin Particle under Stationary and Abrupt Heating, Proc. 1st Int. Symp. Micro and Nano Technology, (2004), CD-ROM, Paper No. XXXIV-C-04.

(11) Ishizuka, S., Characteristics of Tubular Flames, Progress in Energy and Combustion Science, Vol.19, (1993), pp.187-226, Pergamon Press, Oxford.

(12) Nakano, M., Minakuchi, H., Simokuri, D. and Ishizuka, S., Flame Stabilization by a Tubular Flame, Proc. 39th Symp. (National) Combustion, (in Japanese), (2001), pp.191-192. 